disability and dependence on care. The progressive ageing of the population promoted by the demographic transition and the advent of chronic-degenerative diseases increasingly show the role of caregiver as a profession, together with the need to evaluate repercussions for their well-being and health by caring. In comparison the formal and informal caregivers, the concerns with regard to quality of life was similar. The objective of the study was to evaluate the caregiver's profile and establish a relation among the more intense burden and the degree of elderly's dependence.

Methods A descriptive cross-sectional study with 157 caregivers and 159 patients (February-September 2016) was carried out with a Preventive Medicine Program, a systematised home care service (HCS) at Unimed Health Operator, in Poços de Caldas-MG. The burden of caregivers was evaluated using Zarit Burden Interview (ZBI); to evaluate self-care capacity, the Palliative Performance Scale (PPS) was applied. Statistical analysis was performed using the Mann-Whitney test, using $\mathrm{p}<0.05$.

Results Patients were divided in 2 groups $(87 \%$ PPS $<60$, $13 \%$ PPS $>60$, average PPS $=48.89$ ), demonstrating that most patients were highly care dependent. $42,5 \%$ of the caregivers have moderate-intense burden for the more dependent patient's group with PPS $\leq 60$ compared to only $2.5 \%$ with moderate burden in less dependent group of patients with PPS $>60 \quad(\mathrm{p}<0,001)$. Average $\mathrm{ZBI}=46.36$; Impact on care $=40 \%$; Interpersonal relationship $=32 \%$; Expectation with care $=61 \%$; Perceived self-efficacy $=51 \%$. Caregiver profile: mostly female (mean age $=58$ years-old); the burden is only influenced by the level of dependency of the patient $(\mathrm{p}<0,001)$.

Discussion There is a moderate-severe burden for caregiver's patients assisted by Unimed's HCS, and this was directly related to the level of dependence measured by PPS. These data is in accordance to a Portuguese study, which identified a moderate-intense burden in $37.2 \%$ of the caregivers.

\section{REPORTING OCCUPATIONAL BLOOD EXPOSURES: DOES IT RELATE TO OUR KNOWLEDGE ON TRANSMISSION RISKS?}

${ }^{1}$ A Jones*, ${ }^{2}$ B Hayes. 'Specialist Registrar in Occupational Medicine, Beaumont Hospital, Dublin, Ireland; ${ }^{2}$ Consultant Occupational Physician, Beaumont Hospital, Dublin, Ireland

\subsection{6/oemed-2018-ICOHabstracts.958}

Introduction Occupational Blood Exposures (OBEs) are a significant occupational hazard in the healthcare sector. This study aimed to assess the practice of reporting OBEs among healthcare workers (HCWs), namely doctors, nurses and healthcare assistants (HCAs), and if there is a difference in the reporting practice between these groups. Whether a HCWs knowledge of the risks associated with an OBE, such as the risk of transmission of various blood borne viruses, has an influence on their likelihood to report an OBE was also considered.

Methods A questionnaire was distributed to all Non-Consultant Hospital Doctors (NCHDs), all nurses and all HCAs working in a large tertiary hospital. The survey was in both paper and electronic format. It assessed both the individuals past exposures and knowledge of the associated risks.

Results Of the study participants, 25.4\% were doctors, $63.3 \%$ were nurses and $11.2 \%$ were HCAs. $17.8 \%$ had experienced an OBE in the previous 12 months. Doctors accounted for the largest group, with $42 \%$ having a recent exposure. Doctors were also significantly less likely than their nursing and HCA colleagues to report an OBE, with $73.9 \%$ having an unreported exposure in the previous 12 months.

Two of four questions assessing the healthcare workers knowledge of the risks of OBEs showed a statistically significant difference in the knowledge across the three groups, with both doctors and nurses displaying a greater knowledge than HCA's.

Discussion The true prevalence of OBEs in healthcare workers is likely significantly higher than reported. The main reasons identified for not reporting exposures were due to the HCW risk assessing the injury themselves, and deeming it not significant. This study supports the hypothesis that there is a relationship between the knowledge a HCW has on the risks associated with OBE's and their likelihood to report an exposure, however further research is required in order to quantify the magnitude of this relationship.

\section{MANAGEMENT OF OCCUPATIONAL RISKS IN HOSPITALS: CASE OF CHR - ATAKPAMÉ (TOGO)}

${ }^{1} \mathrm{~K}$ Kara-Peketii, ${ }^{1}$ YA Agbobli, ${ }^{2} \mathrm{~F}$ Pandao. ${ }^{1}$ University of Lomé (TOGO); ${ }^{2}$ Pôle santé travail environnement et recherche (TOGO)

\subsection{6/oemed-2018-ICOHabstracts.959}

Introduction The hospital is a multi-risk workplace. To the risk of any organisational structure are added those linked to the essence of its activity: the presence of pathogens, the use of sensitive technologies or devices, the coexistence of stress, suffering and death.

Methods This is a prospective study that took place from December 18, 2015 to march 18, 2016. It is part of occupational safety and health.

Results The approach to psycho-social risk management at CHR Atakpamé shows that the staff of this hospital is exposed primarily to biological, mechanical hazards, particularly blood exposition accident, ergonomic risk, and stress. They are also exposed to other risks related to postures, noise, lighting and thermal environments.

Discussion More than 61\% of CHR Atakpamé staff felt that they did not have access to occupational hazard information; $86 \%$ stated that they did not have a good knowledge of institutional procedures related to occupational accidents and diseases. $36 \%$ of the staff reported their occupational accidents and only $2 \%$ of them were recognised. However, of the $46 \%$ professional diseases reported none had been recognised.

In Ben Rahal's study, out of 10 reported occupational accidents, only one was recognised due to a lack of information on the reporting procedure.

\section{CHEST X-RAY SCREENING FOR PRE-EMPLOYED HEALTHCARE WORKERS IN A PRIVATE HOSPITAL, THAILAND}

Worrapan Karnjanakantorn. Bangkok Hospital Group

\subsection{6/oemed-2018-ICOHabstracts.960}

Background Thailand is classified by WHO as one of the 22 countries in the world with the highest TB burden. With a 